Vol. 4, No. 4, p. 63-65, 2021

\title{
Perspective
}

\section{Development of adsorption ratio equation and state equation of liquid and their geological significance}

\author{
Junqian $\mathrm{Li}^{\oplus *}$ \\ School of Geosciences, China University of Petroleum (East China), Qingdao 266580, P. R. China
}

Keywords:

Adsorption ratio equation

state equation of liquid

porous media

shale

Cited as:

$\mathrm{Li}$, J. Development of adsorption ratio equation and state equation of liquid and their geological significance. Capillarity, 2021, 4(4): 63-65, doi:

10.46690/capi.2021.04.01

\begin{abstract}
:
There have been many theories to describe adsorbed or free gas. However, quantitative description of the occurrence characteristics of liquids in porous media has always been a great challenge due to a lack of basic theory. Through years of research, two theoretical equations, i.e., adsorption ratio equation and state equation of liquid, have been proposed to describe the characteristics of liquids in porous media, and revealed the mechanism of liquid occurrence. Further, a quantitative evaluation technology for the microscopic distribution of liquids was established by combining nuclear magnetic resonance theory. This research will be of great significance for studying the microscopic distribution of liquids in tight reservoirs, such as shale, coal, and tight sandstone.
\end{abstract}

There are many experimental or theoretical studies on gas adsorption to porous media (Gensterblum et al., 2010; Gasparik, 2012; Tian et al., 2016; Pozo et al., 2017; Xiong et al., 2021), and free gas can also be easily described by the state equation of gas ( $\mathrm{Li}$ et al., 2020a). However, there are relatively few studies on the occurrence of liquids in porous media. The biggest difference from the occurrence of gas (such as methane) is that the occurrence of liquids is almost unaffected by fluid pressure, which has been verified by molecular dynamics simulation. Therefore, previously established adsorption models and state equation for gases (both two are functions of pressure) are no longer applicable to liquids. Though previously several classical equations were commonly used to describe the state of liquids such as Van Der Waals equation (Van der Waals, 1873), Tait equation (Tait, 1888) and Peng and Robinson (PR) equation (Peng and Robinson, 1976), these equations are appropriate for liquids in a completely free state because they did not consider the adsorption phenomenon of liquids on pore surface. Overall, research on the microscopic occurrence of liquids including adsorbed and free states within porous media is relatively inadequate.
*Corresponding author.
E-mail address: lijunqian@upc.edu.cn (J. Li).

2709-2119 (C) The Author(s) 2021

Received August 10, 2021; revised August 20, 2021; accepted August 21, 2021; available online August 23, 2021.
As a case study, the shale reservoir develops abundant nano-scale pores and exists a significant nano-effect, which causes that the adsorbed fluid accounts for a relatively high proportion and cannot be ignored. Based on the characteristics that both the liquid oil and water in shale pores coexist as adsorbed and free phases (Fig. 1), two theoretical equations describing the occurrence of liquids in shale pores were proposed, which are called as "adsorption ratio equation" and "state equation of liquid". These two equations established a connection between characteristic parameters of fluid occurrence (adsorbed amount, free amount, densities of adsorbed and free phases, adsorption thickness) and pore-throat structure parameters of porous media (pore size and shape, pore volume, specific surface area). At the same time, the relationship of fluid occurrence, fluid mobility with microscopic porethroat is established. Moreover, the effects of temperature and wettability are implied in the equations, and are reflected in the density and thickness of adsorbed phase. At present, these two equations have been confirmed by experimental data $(\mathrm{Li}$ et al., 2019, 2020b).

The adsorption ratio equation can be expressed as ( $\mathrm{Li}$ et al., 2018):

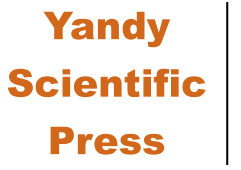




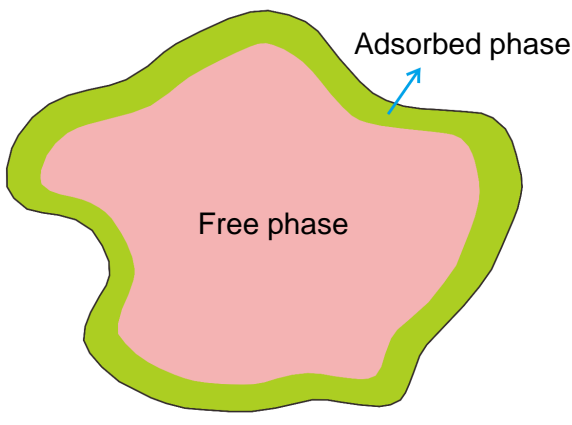

Fig. 1. Liquid occurrence pattern in the pores of porous media.

$$
r_{a}=\frac{1}{1+\frac{\rho_{2}}{\rho_{1}}\left(\frac{d_{m}}{F H}-1\right)}
$$

Or another form:

$$
r_{a}=\frac{1}{1+\frac{\rho_{2}}{\rho_{1}}\left(\frac{V}{S H}-1\right)}
$$

where $r_{a}$ is the mass ratio of adsorbed phase to total fluid, fraction; $H$ is the thickness of adsorbed phase, nm; $\rho_{1}$ and $\rho_{2}$ are the densities of adsorbed and free phases, respectively, $\mathrm{g} / \mathrm{cm}^{3} ; d_{m}$ is the pore diameter, $\mathrm{nm} ; F$ is the pore shape factor, dimensionless; $V$ and $S$ are the pore volume and specific surface area of porous media, with units of $10^{-3} \mathrm{~cm}^{3} / \mathrm{g}$ and $\mathrm{m}^{2} / \mathrm{g}$, respectively.

The state equation of liquid can be written as ( $\mathrm{Li}$ et al., 2019):

$$
\frac{V}{S}=\tau H\left(\frac{\rho_{1}}{\rho_{2}} \frac{Q_{f}}{Q_{a}}+1\right)
$$

where $Q_{a}$ and $Q_{f}$ are the adsorbed and free amounts, respectively, $\mathrm{mg} / \mathrm{g} ; \tau$ is the correction coefficient, which is usually taken as one, dimensionless.

The adsorption ratio equation is used to describe the mass ratio of the adsorbed phase to total amount of fluid in the pores when the liquid coexists in adsorbed and free phases under certain temperature and pressure conditions. At present, this equation has been applied to four aspects. (a) To determine the lower limit of pore size $\left(d_{\mathrm{min}}\right)$ that liquid can flow in porous media, which is equal to the product of pore shape factor $(F)$ and adsorption thickness $(H)$ (i.e., $d_{\min }=F H$, where $F=2$, 4 , and 6 represent parallel plate-shaped pores, column-shaped pores, and spherical pores, respectively). (b) To analyze the ratio of adsorbed and free phases in pores. The adsorption ratio is lower when the ratio of pore size $\left(d_{m}\right)$ to lower limit $\left(d_{\min }\right)$ is larger; when the ratio of adsorbed phase density $\left(\rho_{1}\right)$ to free phase density $\left(\rho_{2}\right)$ is greater, the adsorption ratio is higher. (c) To evaluate the mobility of liquid in porous media, that is, the larger the adsorption ratio is, the worse the fluid mobility occurs; (d) Combining the state equation of liquid and nuclear magnetic resonance (NMR) theory, relaxation rate of rock surface can be determined.

The state equation of liquid is a general expression derived based on the adsorption ratio equation to describe the occurrence state of liquid in pores. This equation theoretically reveals a linearly positive relationship between the ratio of pore volume to specific surface area of porous media and the ratio of free amount to adsorbed amount of fluid in pores (Fig. 2a). According to the intercept and slope of this linear curve, the density and thickness of adsorbed phase can be obtained using Eq. (3). Adsorbed and free amounts can be obtained by saturation-centrifugation experiment; pore volume and specific surface area can be obtained by lowtemperature nitrogen adsorption, wet weight method and other experiments. In addition, combined with the adsorption ratio equation and NMR theory, the surface relaxation rate can be determined. As shown in Fig. 2b, surface relaxation rates of shales are negatively related to total organic carbon content (TOC). In the past, the NMR $T_{2}$ spectrum was compared with pore size distribution to determine surface relaxation rate, but this method did not consider the influence of pore shape. Due to the lack of mathematical equations describing the occurrence of liquids, three key parameters (density and thickness of adsorbed phase, surface relaxation rate) are difficult to determine through experiments. These two equations provide a new theoretical basis for the determination of adsorption parameters and surface relaxation rate.

Based on these two equations and classic NMR theory, a quantitative evaluation technology for the microscopic distribution of adsorbed and free fluids in shales has been established (Fig. 3). In this technology, an important innovation is the integration of the adsorption ratio equation into the NMR theory. Commonly, the calculation formula of NMR transverse
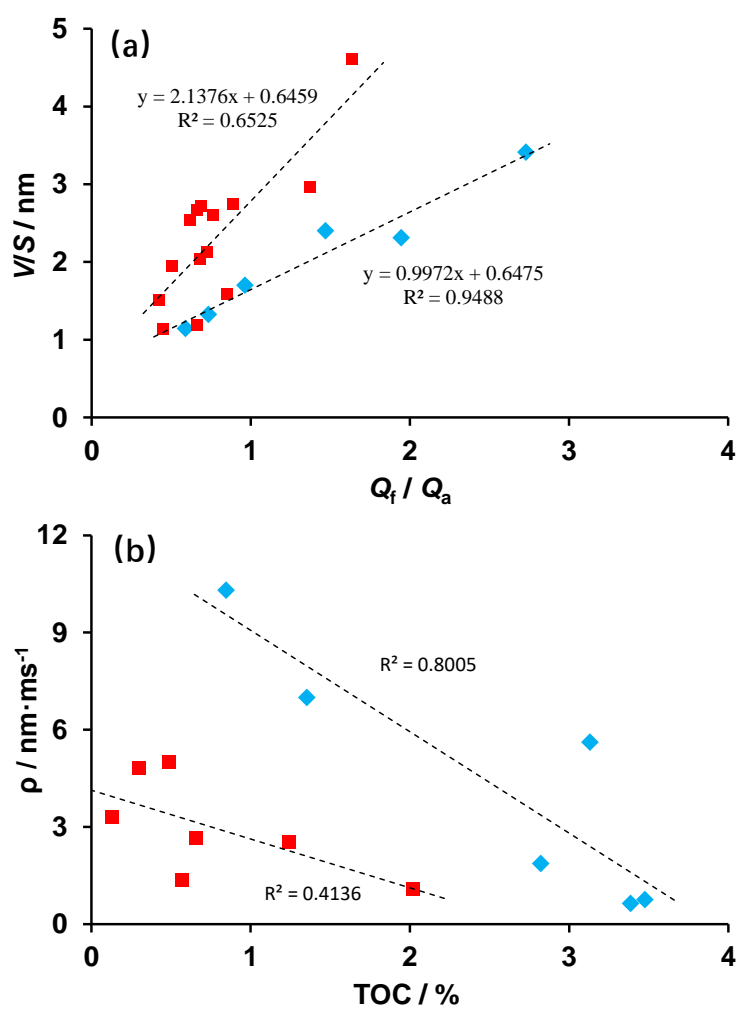

Fig. 2. Experimental verification of the state equation of liquid (a) and surface relaxation rate analysis result (b). In the figures, baby blue diamond indicates distilled water in marine shales from the southeastern Sichuan basin at $20{ }^{\circ} \mathrm{C}$; red square $\mathbf{\text { indicates }} \mathrm{n}$-dodecane in lacustrine shales from the Dongying sag at $20^{\circ} \mathrm{C}$. 


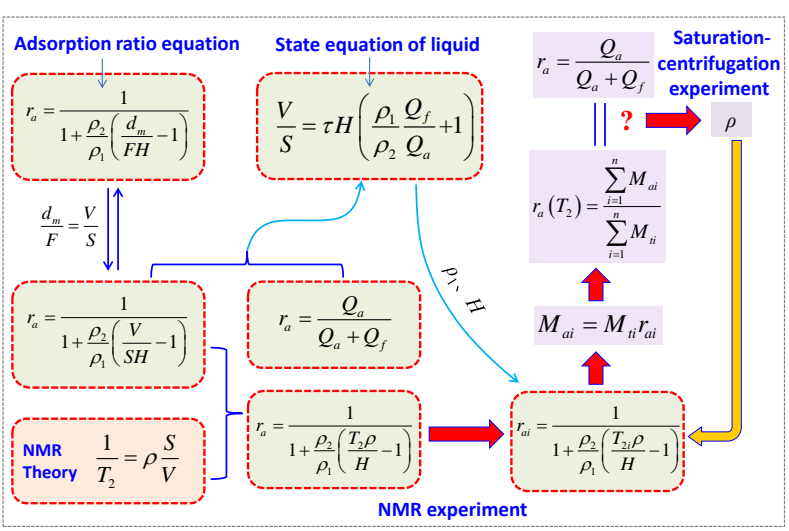

Fig. 3. Quantitative evaluation technology for the microscopic distribution of liquids. In the figure, $M_{a i}$ indicates the signal amplitude of adsorbed fluid at the $T_{2 i}$ value; $M_{t i}$ indicates the total signal amplitude the $T_{2 i}$ value; $r_{a}\left(T_{2}\right)$ indicates the adsorption ratio obtained by NMR data.

relaxation time $T_{2}$ is written as:

$$
\frac{1}{T_{2}}=\rho \frac{S}{V}
$$

where $T_{2}$ is the lateral relaxation time, ms; $\rho$ is the surface relaxation rate, $\mathrm{nm} / \mathrm{ms}$.

Based on the adsorption ratio equation, it can be obtained:

$$
r_{a i}=\frac{1}{1+\frac{\rho_{2}}{\rho_{1}}\left(\frac{T_{2 i} \rho}{H}-1\right)}
$$

where $T_{2 i}$ is the $i$-th $T_{2}$ value on the NMR $T_{2}$ spectrum, $\mathrm{ms} ; r_{a i}$ is the adsorption ratio corresponding to the $T_{2 i}$ value $\left(0<r_{a i} \leq 1\right.$, when the calculated value $r_{a i}>1$, take $\left.r_{a i}=1\right)$, fraction.

As we determine the adsorption parameters and surface relaxation rate, microscopic distribution of adsorbed and free fluids can be obtained using the technology, as shown in Fig. 3. This technology has been applied to marine shale gas reservoirs in the Sichuan Basin, and the lacustrine shale oil reservoirs in the Dongying Sag, and revealed the microoccurrence of oil/water in the pores of shale matrix, which providing theoretical support for "sweet spot" evaluation and efficient development of shale oil and gas.

\section{Acknowledgement}

This work was supported by the National Natural Science Foundation (No. 41972123).

\section{References}

Abda, A. S., Elhafyana, E., Siddiquia, A. R., et al. A review of the phenomenon of counter-current spontaneous imbibition: Analysis and data interpretation. Journal of Petroleum Science and Engineering, 2019, 180: 456-470.

Gasparik, M., Ghanizadeh, A., Bertier, P., et al. High-pressure methane sorption isotherms of black shales from the Netherlands. Energy \& Fuels, 2012, 26: 4995-5004.

Gensterblum, Y., Hemert, P. V., Billemont, P., et al. European inter-laboratory comparison of high pressure $\mathrm{CO}_{2}$ sorption isotherms II: Natural coals. International Journal of Coal Geology, 2010, 84(2): 115-124.

Li, J., Lu, S., Cai, J., et al. Adsorbed and free oil in lacustrine nanoporous shale: A theoretical model and a case study. Energy \& Fuels, 2018, 32(12): 12247-12258.

Li, J., Lu, S., Zhang, P., et al. Estimation of gas-in-place content in coal and shale reservoirs: A process analysis method and its preliminary application. Fuel, 2020a, 259: 116266.

Li, J., Lu, S., Zhang, P., et al. Quantitative characterization and microscopic occurrence mechanism of pore water in shale matrix. Acta Petrolei Sinica, 2020b, 41(8): 979990. (in Chinese)

Li, J., Wang, S., Lu, S., et al. Microdistribution and mobility of water in gas shale: A theoretical and experimental study. Marine and Petroleum Geology, 2019, 102: 496507.

Peng, D. Y., Robinson, D. B. A new two constant equation of state. Industrial and Engineering Chemistry Research Fundamentals, 1976, 15: 59-64.

Pozo, M., Pino, D., Bessieres, D. Effect of thermal events on maturation and methane adsorption of Silurian black shales (Checa, Spain). Applied Clay Science, 2017, 136: 208-218.

Tait, P. G. Physics and chemistry of the voyage of H. M. S. challenger, Vol. 2, Part 4. London, UK, HMSO, 1888.

Tian, H., Li, T., Zhang, T., et al. Characterization of methane adsorption on overmature Lower Silurian-Upper Ordovician shales in Sichuan Basin, southwest China: Experimental results and geological implications. International Journal of Coal Geology, 2016, 156: 36-49.

van der Waals, J. D. Over de Continuiteit van den Gasen Vloeistoftoestand (On the continuity of gaseous and liquid states). Leiden, University of Leiden, 1873.

Xiong, F., Rother, G., Gong, Y., et al. Reexamining supercritical gas adsorption theories in nano-porous shales under geological conditions. Fuel, 2020, 287(44): 119454. 